\title{
Coulisses
}

Revue de théâtre

5 | Hiver 1992

Varia

\section{Le Monte-plats}

\section{Lucile Garbagnati}

\section{OpenEdition}

Journals

Édition électronique

URL : http://journals.openedition.org/coulisses/1705

DOI : $10.4000 /$ coulisses. 1705

ISSN : 2546-9460

\section{Éditeur}

Presses universitaires de Franche-Comté

\section{Édition imprimée}

Date de publication : 1 janvier 1992

Pagination : 10-12

ISSN : 1150-594X

\section{Référence électronique}

Lucile Garbagnati, «Le Monte-plats », Coulisses [En ligne], 5 | Hiver 1992, mis en ligne le 04 juillet 2017 , consulté le 22 octobre 2019. URL : http://journals.openedition.org/coulisses/1705 ; DOI : 10.4000/ coulisses. 1705

Ce document a été généré automatiquement le 22 octobre 2019

Coulisses 


\section{Le Monte-plats}

\section{Lucile Garbagnati}

« Deux personnes dans une pièce. Je me sers très souvent de cette image de deux personnes dans une pièce. Le rideau se lève, et une question se pose à moi avec force : Que va-t-il arriver aux deux personnes qui sont là dans cette pièce? Quelqu'un va-t-il ouvrir la porte et entrer?»

H. Pinter.

« La menace est une question de circonstances.

Elle ne vient pas de gens sinistres ou extraordinaires, mais de gens ordinaires comme

vous et moi. À un certain moment je deviens brusquement une menace dans votre vie, ou vous devenez une menace dans la mienne. » H. Pinter. 


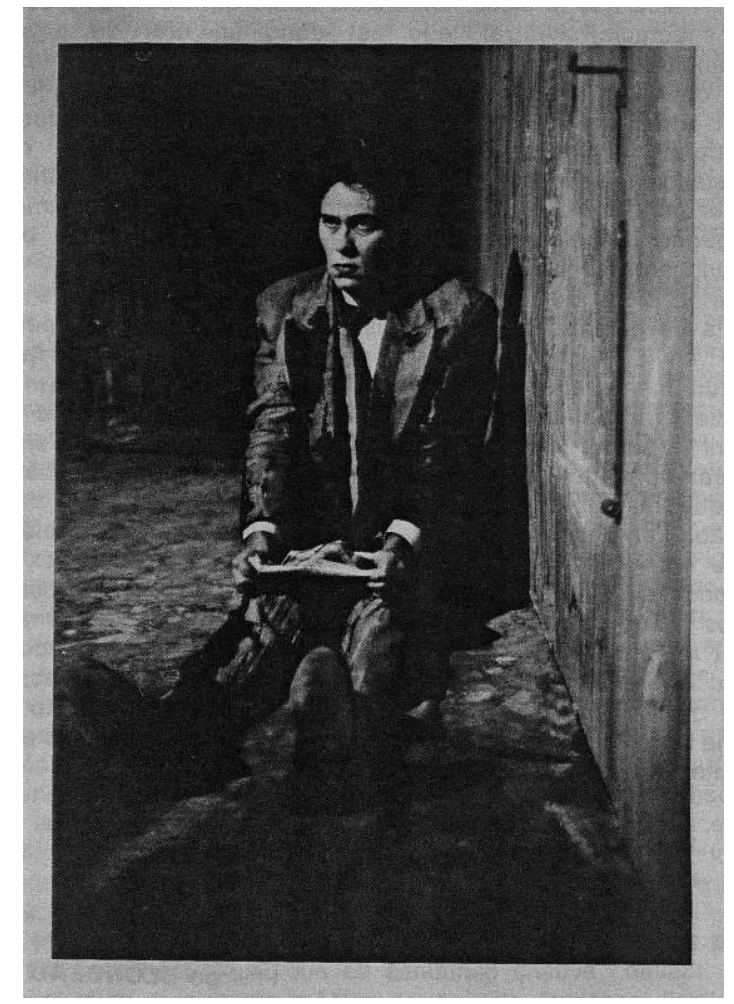

Le Monte-plats.

Photo Y. Vaucher, Espace Images.

1 Hall de l'Espace Besançon-Planoise. Une vitrine. À l'intérieur, un service à thé de porcelaine blanche. Aucune explication. Qu'est-ce que cela veut dire?

2 Dans la Petite Salle, la scène transformée en un entonnoir gris sale. Côté cour, côté jardin, deux portes hautes et étroites, plus que d'ouverture, elle donne l'impression de fermeture. Au fond de cet espace qui va en se rétrécissant, une énorme poignée de nickel étincelle sous un éclairage en douche impitoyable. Deux hommes sont affalés. Leurs costumes sont maculés. Leurs visages grimés évoquent à la fois les gangsters des années trente, et les clowns tristes.

3 D'entrée on sait que dans ce lieu clos, il n'y a pas d'issue. Cette image sinistre est rendue plus menaçante par la musique oppressante de Manuel Poletti.

4 Gus et Ben sont là. Ils attendent. En attendant, ils tuent le temps en parlant, ils sont arrivés la nuit. Ils attendent, comme chaque fois d'ailleurs, l'ordre de tuer. Mais l'ordre tarde. Ben commente les faits divers d'un journal. Gus fait et refait le maigre inventaire de son sac. Il va aux toilettes, franchit la porte étroite, on entend la chasse d'eau, il revient. Tous deux voudraient une tasse de thé, mais ils n'ont pas la pièce qui leur permettrait d'ouvrir le compteur à gaz. Ces banalités répétées font sourdre la violence des deux hommes. Le plancher montant, les jeux de lumière accentuent la taille et la carrure de Ben. Gus se soumet.

5 Soudain un grand fracas. Le panneau étroit du fond n'est autre que la porte d'un monte-plats auquel l'énorme poignée donne accès. L'attente des hommes bascule. Le monte-plats envoie des commandes de plus en plus saugrenues et sur un rythme de plus en plus rapide. Faut-il les satisfaire ? Comment? 
6 La tension monte. Ben ne doute pas un instant qu'il faille exécuter les commandes quelles qu'elles soient, même s'ils n'ont pas grand'chose qui y correspondent. Gus aurait tendance à se rebiffer pour conserver ses maigres possessions. Dans un moment d'accalmie des commandes ils répètent les gestes du crime.

7 Gus sort une nouvelle fois. Une nouvelle commande arrive que Ben enregistre. C'est le nom de la victime. On entend la chasse d'eau. Gus entre par l'autre porte, poussé par une force extérieure. Il est sans veston, sans revolver. Ben dégaine.

8 De ce texte à suspense, façon Hitchcock, dont la cocasserie et l'humour noir ne sont pas absents, J.-M. Potiron fait une tragédie qui a gagné en sobriété et en densité au fil des répétitions.

9 Ces deux hommes, ne sont que des marionnettes impuissantes. Ben surdimensionné par la pente et l'éclairage, ne peut manifester sa violence qu'en choisissant dans le journal les faits divers les plus cruels, puis en le tordant de ses fortes mains. Gus tente d'affirmer son autonomie en inventoriant ses biens personnels et en jouant avec son corps. Ils seront absorbés par le Monte-plats, véritable Moloch insatiable, qui exige toute l'attention, récuse toute autre préoccupation que le soin de son service, ordonne le sacrifice.

10 L'image finale laisse les deux personnages face à face, dans l'attitude d'un arrêt sur l'image : Ben va-t-il tirer?

11 À chacun de répondre.

12 En sortant on retrouve dans le hall la luminescente blancheur du service à thé enfermé dans sa vitrine. À qui sert-il ?

13 À chacun de répondre. 